\title{
Comparative Study on the Efficiency of Intermaxillary Elastic Polymers used in the Treatment of Skeletal Class II Malocclusions in Growing Patients
}

\author{
LUMINITA LIGIA VAIDA ${ }^{1}$, RALUCA DIMAㄹ, EMILIA ALBINITA CUC ${ }^{1}$, BIANCA MARIA NEGRUTIU ${ }^{1}$, ABEL EMANUEL MOCA ${ }^{1}$, \\ IOANA ELENA LILE ${ }^{2}$, DELIA DARAGIU ${ }^{3 *}$, ALEXANDRU ZALANA ${ }^{4}$, ELENA LUMINITA ALBERT ${ }^{4}$, BIANCA IOANA TODOR ${ }^{1}$ \\ ${ }^{1}$ University Oradea, Faculty of Medicine and Pharmacy, Department of Dentistry, 1 Universitatii Str., 410087, Oradea, Romania \\ ${ }^{2}$ Vasile Goldis Western University of Arad, Faculty of Medicine, Pharmacy and Dental Medicine, Department of Dentistry, 94-96 \\ Revolutiei Blvd., 310025, Arad, Romania \\ ${ }^{3}$ University Titu Maiorescu, Faculty of Dental Medicine, 67A Gheorghe Petrascu Str., 031593, Bucharest, Romania \\ ${ }^{4}$ University of Medicine, Pharmacy Sciences and Technology, Faculty of Dental Medicine, 38 Gh. Marinescu Str., 540139, \\ Targu Mures, romania
}

The aim of this study was to evaluate the efficiency in using intermaxillary elastics to stimulate mandibular growth and advancement in orthodontic patients diagnosed with skeletal Class II malocclusion as well as to compare the use of these Class II elastics in two different therapeutic approaches. The sample consisted of 60 orthodontic patients aged 10-15 years, 34 girls and 26 boys. The sample was divided into two equal groups (each consisting of 30 patients). Patients belonging to the first group (Group 1) were subjected to 1/ $4^{11}-6.0$ oz elastics and were advised to change the elastic every 24 hours. Patients belonging to the second group (Group 2) were subjected to 1/4"- 4.5 oz elastics but with a recommendation to change the elastics every 12 hours. In order to evaluate the effectiveness of these two types of Class II elastics on mandibular growth and advancement, the value of the SNB angle at the beginning of the treatment (T1) was compared with the value of the SNB angle after 5 months of wearing intermaxillary elastics (T2). All patients showed statistically significant increased values of the SNB angle during the orthodontic treatment $(p<0.001)$. Patients in Group 2 showed a significantly higher statistical increase $(p<0.05)$ than patients in Group 1.

Keywords: Class II elastics, Class II malocclusions, growing patients

Class II malocclusion is considered to be one of the most frequent problems present in orthodontic patients. Literature offers many information on the prevalence of Class II malocclusion, such as: in Europe $33.51 \%$, in the United States 34.3\%, in Latin America 7\% [1,2]. According to Thilander et al., the prevalence of Class II malocclusion in Colombia represents $20.8 \%$, while other authors of the same origin have found a regional prevalence of $43.5 \%$ $[2,3]$. A Tanzanian population presented class II malocclusions in a per cent of 4.4, less than a group of Swedish adolescents, or Asian immigrants [4,5]. Iranian authors have studied children aged between 11-14 years and measured a prevalence of Class II malocclusion of $27.5 \%$, out of which $24.1 \%$ subdivision 1 and $3.4 \%$ subdivision 2 [4]. In Anatolia, from a sample of 2,329 children aged between 12 and 17 years, 40\% presented Class III 1 malocclusion and $4.7 \%$ Class II|2 malocclusion [6].

Class II malocclusion may or may not be accompanied by skeletal imbalances. The mandible may be in a normal position or retruded relative to the maxilla or the maxilla may be protruded or normal relative to the cranial base [710]. Thus, subjects with skeletal Class II malocclusions have a convex profile involving maxillary protrusion, mandibular retrusion or combination of both [11].

The intermaxillary discrepancies can be easily corrected when patients are during the active growth period (children or adolescent). Treatment protocols may vary widely according to the severity of the malocclusion, patient compliance and professional ability [12-14]. The usual treatment options in growing patients include extraoral forces (Head-gears), functional appliances and full fixed appliances with intermaxillary elastics and/or teeth extractions. In adult patients, mild and moderate Class II malocclusions can be adjusted with fixed appliances in combination with intermaxillary elastics with or without teeth extractions, and severe malocclusions can be treated only with fixed appliances in combination with orthognathic surgery. Elastics are among the most widely applied materials in orthodontics. Elastics have been handy orthodontic means for many years; they are a routine measure throughout the whole treatment process. These materials fit two fundamental categories: latex and synthetic rubber (elastomer) (table 1) [15].

According to Tseng et al. [15], taking into consideration the localization and treatment mechanism, elastics are classified as follows:

Table 1

THE MAIN CHARACTERISTICS OF THE ELASTIC MATERIALS USED IN ORTHODONTICS

\begin{tabular}{|c|c|c|}
\hline $\begin{array}{l}\text { Type of } \\
\text { material }\end{array}$ & $\begin{array}{c}\text { Latex Natural } \\
\text { Rubber }\end{array}$ & Synthetic Rubber \\
\hline Origin & Juice of a tree & $\begin{array}{l}\text { Developed from } \\
\text { petrochemicals }\end{array}$ \\
\hline $\begin{array}{c}\text { Main } \\
\text { ingredient }\end{array}$ & $\begin{array}{l}\text { Pure rubber } \\
\text { and water }\end{array}$ & Polyurethane \\
\hline Function & $\begin{array}{c}\text { Intermaxillary } \\
\text { traction }\end{array}$ & $\begin{array}{l}\text { Elastic ligatures } \\
\text { Move the tooth along } \\
\text { the arch }\end{array}$ \\
\hline Renew & $\begin{array}{l}\text { Changed by } \\
\text { the patient } \\
\text { every day }\end{array}$ & $\begin{array}{c}\text { Replaced by the } \\
\text { orthodontist at the } \\
\text { next visit of the } \\
\text { patient }\end{array}$ \\
\hline Form & Ring & Chain \\
\hline
\end{tabular}




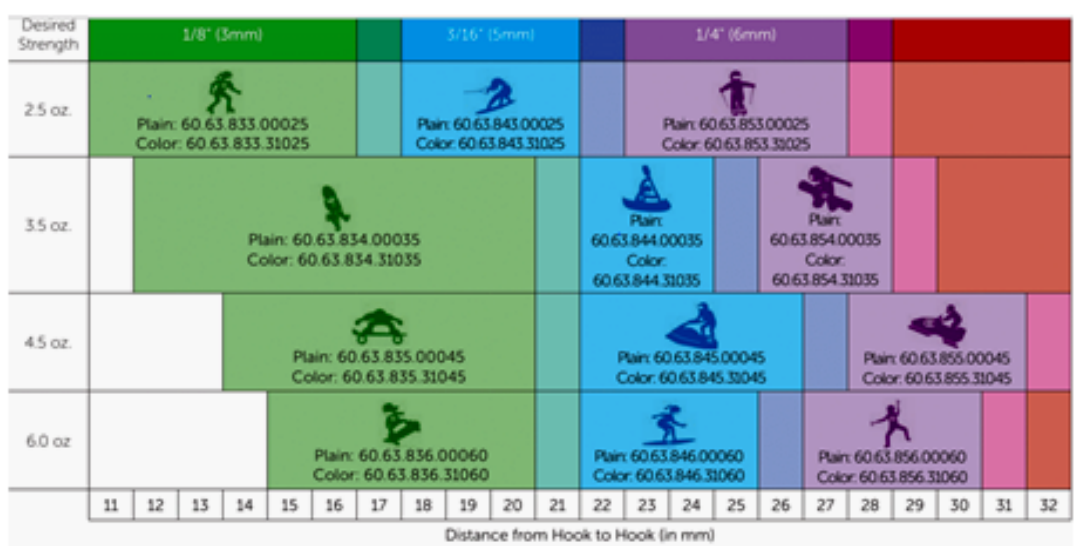

Fig. 1. High-grade latex elastics (considering 2018 OC Catalogue) [18]

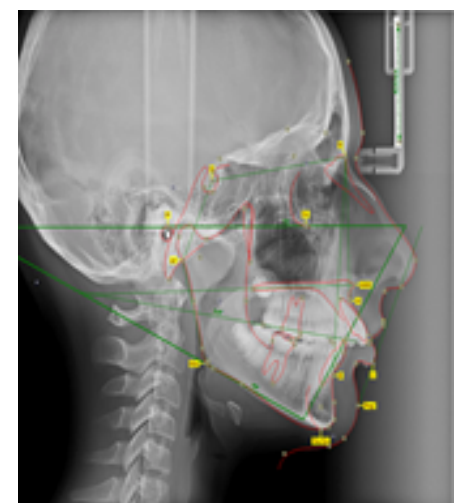

Fig. 2. Cephalometric landmarks (image obtained with Onyx-Ceph)
-Class I Elastics (horizontal, intramaxillary, or intra-arch elastics);

-Class II Elastics (intermaxillary or inter-arch elastics); - Class III Elastics (intermaxillary or inter-arch elastics);

-Anterior Vertical Elastics (intermaxillary elastics: vertical, box or triangle configuration);

-Finishing Elastics (up and down, and continuous intermaxillary elastics);

-Cross bite (trans-alveolar) elastics from buccal or lingual surfaces of affected teeth;

-Diagonal elastics (midline and/or asymmetric elastics).

The force extension value of latex elastics is normally provided by the manufacturers for different types and sizes. The standard force indication is to stretch the elastic to 3 times the original internal diameter in order to achieve the force stated on the package. To get a more consistentforce, previous stretching of elastics is recommended $[16,17]$.

The elastics are made of $95-98 \%$ harmless rubber (butadeine-methil-monoopolymer $\mathrm{C}_{13} \mathrm{H}_{18}$ ) - and small traces of sulfur $(0-0.1 \%)$ and zinc oxide $(0-0.1 \%)$. The manufacturer stated that none of the components are harmful to general health. Although there is a slight increase of allergic reactions in patients with known fruit allergies and in spina bifida patients. Latex elastics come in different sizes (expressed both in inches and in millimeters) with different strengths of elastic force (fig. 1) and are packed in colour-coded bags for quick and easy identification [18].

Non-latex varieties are also available (manufactured from a unique polymer, eliminating the protein and other potential allergy-causing compounds associated with latex) for latex sensitive patients [18].

The aim of this study was to evaluate the efficiency of using intermaxillary elastics to stimulate mandibular growth and advancement in orthodontic patients diagnosed with skeletal Class II malocclusion as well as to compare the use of these Class II elastics in two different therapeutic approaches.

\section{Experimental part}

\section{Material and method}

The sample consisted of 60 orthodontic patients aged $10-15$ years, of which 34 were girls and 26 boys. The study was conducted in accordance to the World Medical Association (WMA) Declaration of Helsinki - Ethical Principles for Medical Research Involving Human Subjects approved by the Ethics Committee of the University Oradea, Romania. All patients were included in the study with their parents' consent. All patients were diagnosed with class II division I malocclusions associated with other dentomaxillary anomalies (e.g.: crowding, isolated dental anomalies, open bite, deep bites etc.). The orthodontic diagnosis was based on clinical examinations and paraclinical examinations (study cast, photostatic examination, orthopantomographic analysis, cephalometric analysis). The following cephalometric skeletal landmarks were used in this study: $\mathrm{S}=$ Sella, $\mathrm{N}=$ Nasion, $A=$ subnasal point, $B=$ sovramental point,$I=$ lower incisor point (fig. 2).

The following inclusion criteria were applied: Class II malocclusion patients with half cusp Class II till full cusp Class II molar and canine dental relationships, convex facial profile, reduced SNB angle (below 78 degrees), increased ANB angle (over 4 degrees), non-extraction patients, normal or reduced IMPA (Incisor - Mandibular Plane Angle below 91 degrees), rapid maxillary expansion (RME) as the first phase of treatment for correcting narrow maxilla. The exclusion criteria were the following: patients whose treatment plan included the application of extraoral forces to the maxilla (since wearing Head-Gear favors mandibular advancement followed by the increase of the value of the SNB angle), patients with temporomandibular joint disorders.

Fixed mechanotherapy with preadjusted appliances (0.022-inch slot) was applied to all patients. In order to correct the mandible growth deficitand/or the mandibular retroposition, the treatment plan of all patients from this study included the use of class II orthodontic mechanics, namely the application of intermaxillary elastics, in two different therapeutic protocols. Thus, the initial sample was divided into two equal groups (each consisting of 30 patients), depending on the therapeutic recommendations related to the elastics' strength and frequency of replacing. Patients belonging to the first group (Group 1) were subjected to $1 / 4^{\prime \prime}-6.0$ oz elastics (fig. 1) with a recommendation to change the elastic every $24 \mathrm{~h}$. Patients belonging to the second group (Group 2) were subjected to $1 / 4^{\prime \prime}-4.5$ oz elastics (fig. 1) but with a recommendation to change the elastics every $12 \mathrm{~h}$. All patients were instructed to wear the elastics all day except during oral hygiene. The elastics were applied at the stage where the patients had dental arches proper dental alignment and leveling, on $0.017 \times 0.025$-inch stainless steel (SS) arch wires, between a crimpable hook applied to the upper SS arch wire, mesial to the canine, and the hook attached to the tubing welded onto the cemented ring on the lower first molar or second molar (fig. 3).

In order to evaluate the effectiveness of these two types of Class II elastics on mandibular growth and advancement, the value of the SNB angle at the beginning of treatment (T1) was compared with the value of the SNB angle after 5 months of wearing intermaxillary elastics (T2). Angular measurements of the SNB angle were 

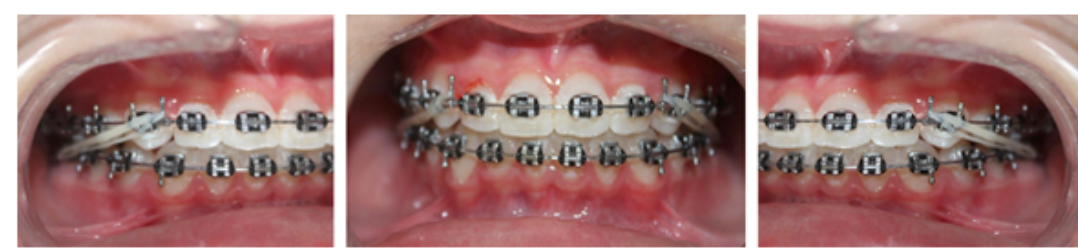

Fig. 3. Class II elastics applied from lower first molars to upper crimpable hooks, located on the arch wire mesial to the canine bracket to move the mandible forward conducted at $\mathrm{T} 1$ and at $\mathrm{T} 2$ for all patients included in this study. The authors used Onyx-Ceph (License type-OSL, version 62), a computerized defalcation program, for these angular measurements (fig. 2).

\section{Data analysis}

All the data from the study was analyzed using IBM SPSS Statistics 20. Quantitative variables were tested for normal distribution using the Shapiro-W ilk Test and were written as means with standard deviations. Analysis in paired groups with non-parametric distribution was made using Related-Samples Wilcoxon Signed Rank Tests. Also, quantitative independent variables with non-parametric distribution were tested using Mann-Whitney U Tests.

\section{Results and discussions}

The evolution of SNB angle post-treatment analyzed for patients within Group 1 is represented in table 2 and figure 4.

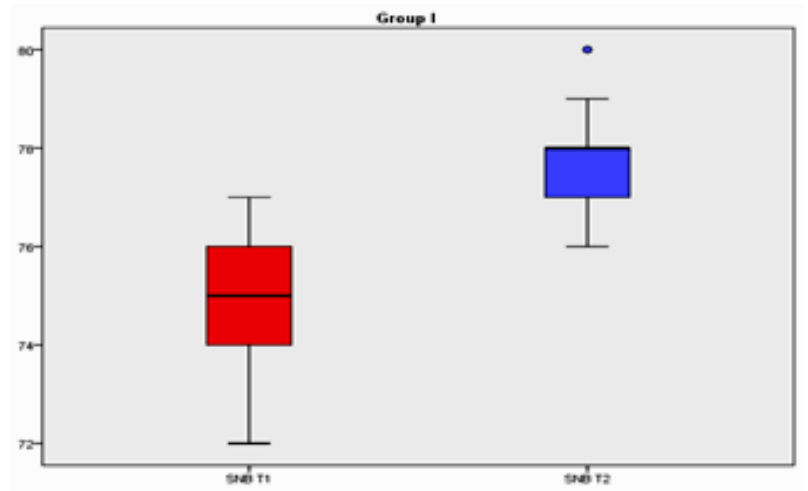

Fig. 4. Evolution of SNB angle post-treatment analyzed for patients within Group 1

Distribution was analyzed using Shapiro-Wilk Test, and proved to be non-parametric for both measurements $(p<0.05)$. The average value of SNB angle before treatment 72 and a maximum of 77 degrees, while the average value of SNB angle after treatment (SNB-T2) was 77.87 \pm 0.860 degrees with a minimum of 76 and a maximum of 80 degrees. According to the Wilcoxon test, differences of SNB angle before and after treatment were statistically significant $(p<0.001)$ showing a significant increase of the SNB angle after treatment (median difference $=+3$ degrees) for the patients within Group 1. (SNB-T1) was $74.87 \pm 1.332$ degrees with a minimum of
Data from table 3 and figure 5 represents the evolution of SNB angle post-treatment analyzed for patients within Groun 2.

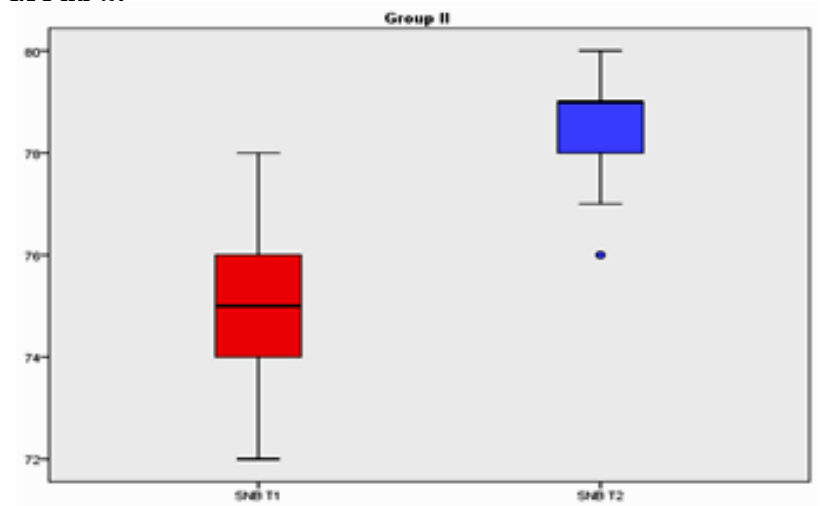

Fig. 5. Evolution of SNB angle post-treatment analyzed for patients within Group 2

Distribution was analyzed using Shapiro-Wilk Test, and proved to be non-parametric for final measurement of SNB angle $(p=0.005)$. The average value of SNB angle before treatment was $75.1 \pm 1.296$ degrees with a minimum of of SNB angle after treatment was $78.63 \pm 1.033$ degrees with a minimum of 76 and a maximum of 80 degrees. According to the Wilcoxon test, differences of SNB angle before and after treatment were statistically significant $(p<0.001)$ showing a significant increase of the SNB angle after treatment (median difference $=+4$ degrees) for the patients within Group 2.

Data from table 4 and figure 6 represents the comparison values of SNB angle, in the studied patients within their groups. Distribution was analyzed using Shapiro-Wilk Test, and proved to be non-parametric $(p<0.05)$ for both groups, also it appeared to be asymmetrical according to the boxplot figure, as such reporting of the results will be using the mean rank of SNB angle.

According to the Mann-Whitney $\mathrm{U}$ test, the differences of the SNB angle evolution between Group 1 and Group 2 were statistically significant $(p=0.011)$, as such the evolution of the SNB angle in Group 2 was significantly higher (mean rank $=35.83$ ) in comparison to Group 1 (mean rank $=25.17$ ).

Class II mechanics applied to growing orthodontic patients with class II malocclusion through intermaxillary 72 and a maximum of 78 degrees, while the average value of the differences between before and after treatment

\begin{tabular}{|c|c|c|c|c|}
\hline Parameter & Average \pm SD & Min-Max & Median & $\mathbf{p}^{*}$ \\
\hline SNB-T1 $\left(p=0.033^{* \bullet}\right)$ & $74.87 \pm 1.332$ & $72-77$ & 75 & \multirow{2}{*}{$\leqslant 0.001$} \\
\cline { 1 - 4 } SNB-T2 $\left(p=0.004^{* \bullet}\right)$ & $77.87 \pm 0.860$ & $76-80$ & 78 & \\
\hline SNB-T2 - SNB-T1 & $3 \pm 0.910$ & $1-5$ & 3 & - \\
\hline
\end{tabular}

Table 2

EVOLUTION OF SNB ANGLE POST-TREATMENT ANALYZED FOR PATIENTS WITHIN GROUP 1

\begin{tabular}{|c|c|c|c|c|}
\hline Parameter & Average \pm SD & Min-Max & Median & \multirow{2}{*}{$\mathbf{p}^{*}$} \\
\hline SNB-T1 $\left(\mathrm{p}=0.149^{* *}\right)$ & $75.1 \pm 1.296$ & $72-78$ & 75 & \multirow{2}{*}{$<0.001$} \\
\hline SNB-T2 ( $\left.=0.005^{* *}\right)$ & $78.63 \pm 1.033$ & $76-80$ & 79 & \\
\hline SNB-T2 - SNB-T1 & $3.53 \pm 0.681$ & $2-4$ & 4 & - \\
\hline
\end{tabular}
Related Samples Wilcoxon Signed Rank Test, ${ }^{* *}$ Shapiro-Wilk Test

Table 3

EVOLUTION OF SNB ANGLE POSTTREATMENT ANALYZED FOR PATIENTS WITHIN GROUP 2 


\begin{tabular}{|c|c|c|c|c|}
\hline Patients groups & Average \pm SD & Min-Max & $\begin{array}{c}\text { Average rank-SNB } \\
\text { difference }\end{array}$ & $\mathrm{P}^{*}$ \\
\hline Group $1\left(p=0.008^{\star \star \star}\right)$ & $3 \pm 0.91$ & $1-5$ & 25.17 & \multirow{2}{*}{0.011} \\
\hline Group $2\left(\mathrm{p}=0.001^{\star \star \star}\right)$ & $3.53 \pm 0.681$ & $2-4$ & 35.83 & \\
\hline
\end{tabular}

Table 4

COMPARISON OF THE DIFFERENCE BETWEEN BEFORE AND AFTER TREATMENT VALUES OF SNB ANGLE IN THE STUDIED PATIENTS WITHIN THEIR GROUPS

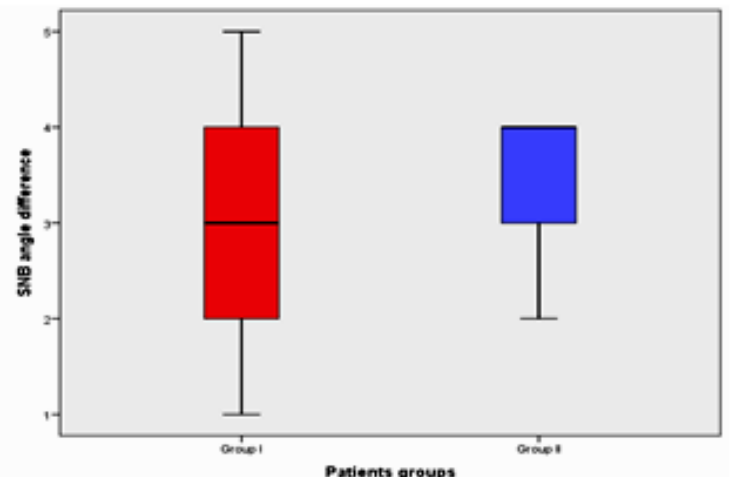

Fig. 6. Comparison of the difference between before and after treatment values of SNB angle in the studied patients within their groups

elastics is an efficient method of correcting mandibular retrognathism.

Complete correction of class II occlusal relationships could not be achieved in 9 patients ( 15 per cent) from the initial sample due to patients' poor cooperation or late therapeutic response. The elastic wear time was extended to over 5 months in these 9 patients.

All patients included in the study had no TMJ side effects during the application of elastics or after using class II elastics. Since all patients included in the study had narrowed upper arches, the subsequent transverse problem was addressed using RME previous to the orthodontic conventional treatmentallowing mandibular advancement in all these patients.

The results of this study revealed that the value of the SNB angle increased statistically significant during the orthodontic treatment in both Group 1 and 2 . This increase in the SNB angle can be explained by the fact that patients were in prepubertal and pubertal growth and by the beneficial effects of Class II intermaxillary elastics. However, patients in Group 2 (those with lighter forces elastics and with indications to change the elastics every $12 \mathrm{~h})$ showed a significantly higher statistical increase $(p<0.05)$ than patients in Group 1 (who received elastics with stronger forces and replacement every $24 \mathrm{~h}$ ).

All patients in this study were in full active growth, prepubertal, pubertal or just after puberty growth, in the bone growth stages from CS2 to CS6 after Bacetti et al 2005. [19] A successful treatment of Class II malocclusion in growing patients depends on the proper orthodontic mechanics, patient cooperation and appropriate growth spur, in ages from 10 to 13 for girls and 11 to 14 for boys [ 8].

In many patients, bite turbos (occlusal stops) are required to avoid any interference between the brackets and the antagonistdental arch. According to their position, bite turbos are classified as anterior and/or posterior [15]. We constructed these bite turbos on the lower or upper first and/or second molars, using composites, glass ionomer cement $(\mathrm{GIC})$ or resin modified glass ionomer cements, with good resistance to masticatory forces [20]. Another alternative is the use of acrylic bite-blocks of thermoplastic or thermo set resins [21]. These bite turbos have the advantage of preventing dental inter-cuspidation, thus allowing greater freedom of mandibular movements so that the mandible can advance easier during the intermaxillary elastic wearing. In a study conducted by
Lira et al. (2014), the authors found that SNB angle increased an average $1.70( \pm 0.650)$ in a sample of 80 growing patients with Class II malocclusion submitted to full orthodontic treatment with standard edgewise appliance and cervical Headgear, without Class II elastics [22]. This may be explained by the overall development of the mandible during the active grow th period as well as by the advancement of the mandible favored by Headgear. In spite of the benefits of the intermaxillary elastics, many authors have attributed several side effects to the use of Class II elastics, e.g. proclination of mandibular incisors, extrusion of maxillary incisors, and even worsened smile aesthetics due to increased gum exposure, loss of mandibular anchorage, extrusion of the mandibular molars and the maxillary incisors, causing clockwise rotation of the occlusal plane and the mandible, less satisfactory from the perspective of skeletal relationships and facial aesthetics [23-25].

An undesirable effect of Class II elastics is the protrusion of the lower anterior teeth as the force is concentrated on the lower anterior segment. This can, however, be prevented by using a pre-torqued wire prior to wearing Class II elastics or using brackets with built-in labial root torque $[26,27]$. Most of the authors have shown that the use of Class II elastics has predominant dentoalveolar effects (e.g.: the dentoalveolar changes comprised $63 \%$ and the skeletal, 37\%) [25,28-31]. J ones et al. (2008) found a tendency of predominantly skeletal effects consequent to the use of Class II elastics [32].

Even if Class II elastics worked primarily through dentoalveolar changes in the mandible, our study shows that Class II elastics stimulate mandibular advancement in growing patients.

Another very important issue refers to the stability of the therapeutic outcome achieved by the use of Class II elastics. In a systematic review on the Correction of Class II malocclusion with Class II elastics conducted by] anson et al. [33], the authors tried to elucidate the controversial issue of the side effects of Class II elastics compared to other methods of Class II malocclusions treatment, as well as the stability of the therapeutic outcome achieved by using elastics. The authors found only four articles on the study of the treatment of Class II malocclusions with elastics only, without other treatment appliances or protocol, and seven articles on comparative studies of the treatment of Class II malocclusions with Class II elastics and other appliance or protocol. The elastic strength used in those articles varied from $2.5 \mathrm{oz}$ [30] to $4 \mathrm{oz}$ [31] with a mean of elastic force of $2.6 \mathrm{oz}(73.7 \mathrm{~g})$ and the duration of active treatment with Class II elastics was mentioned in only one article as being 8.5 months. The same authors concluded that, in the long term, there are no relevant differences between the effects produced by functional appliances and Class II elastics, since both protocols have a predominance of dentoalveolar effects as an enduring result; there is no strong evidence that they have mainly side effects. The same authors suggested that further detailed description of Class II elastics protocols of usage (e.g.: diameter, strength, prescription, appropriate wire, and periods of wear) are required [33]. Kanchana et. al (2000) and Wang et al. (2007) suggest that most of the elastics lose $50 \sim 70 \%$ of their initial force during the first day of application [34,35]. 
We consider that it is important for the patient to change the elastics at least once a day. Replacement of elastics at a 12-hour interval provides a better control of the force value and a decrease the variation of the elastic forces values. In many cases, therapeutic objectives include both dentoalveolar changes and skeletal changes. In growing patients there are no dentoalveolar changes which are desired to be minimized, intermaxillary elastics can be successfully applied also using skeletal anchorage, on miniscrew or miniplates [36,37]. In our study all patients needed skeletal correction as well as dentoalveolar changes, that is why we have opted for Class II elastics directly applied on the hooks from arch wires and from molar bands. Skeletal correction is possible also eith Twin Block which protrude the mandible, to improving jaw relationships and to correct of Class II [40]. Based on this research and on our experience in achieving the correction of Class II malocclusions with a satisfactory skeletal response, the appropriate prescription for Class II elastics is $1 / 4^{11}-4.50 z$, with a change of twice a day, and with 5-8 months of wear depending on the severity of malocclusion and patient compliance.

Correcting class II malocclusions using intermaxiallary elastics is a cost-effective method but requires a proper patient compliance. It is very important that patients be properly instructed on the application and change schedule of the elastics and that the orthodontist check the patient abilities of applying the elastics at the beginning and during each patient consultation.

Introducing the elastic wear stage can cause or increase in patients' stress or anxiety, followed by their refusal [3841]. In order to prevent these inconveniences patients must be informed before the beginning of the orthodontic treatment that, in order to obtain favorable therapeutic results with benefits on patients' facial appearance, selfesteem and quality of life, it is important to include in the treatment plan the stage of wearing intermaxillary elastics.

\section{Conclusions}

Class II elastics are an effective therapeutic method for the correction of occlusion relationships and for the stimulation of the mandibular growth and advancement in growing patients.

The effectiveness of these elastics depends on the prescribed intensity of the elastic forces and on the frequency of the elastic replacement.

According to this study, better therapeutic results are obtained when elastics of lighter forces are applied with a more frequent replacement, twice a day instead of once a day.

\section{Reference}

1.UREGO-BURBANO, P.A., JIMENEZ-ARROYAVE, L.P., LONDONOBOLIVAR, M.A., ZAPATA-TAMAYO, M., BOTERO-MARIACA, P., Rev Salud, Publica (Bogota), 13, No. 6, p. 1010-21, Dec 2011.

2.ALHAMADI, M.S., HALBOUB, E., SALAH-FAYED, M., LABIB, A., ELSAAIDI, C., Dental Press J Orthod., 23, No. 6 e.10, Nov-Dec 2018, p. 40. 3.THILANDER, B., PENA, L., INFANTE, C., PARADA, S.S., de MAYORAGA, C., Eur J Orthod, 23, No. 2, Apr 2001, p. 153-67.

4.BORZABADI-FARAHANI, A., ESLAMIPOUR, F., Eur J Orthod., 31, no. 5, Oct 2009, p. 477-84.

5.J OSEFSSON, E., BJ ERKLIN, K., LINDSTEN, R., European J ournal of Orthodontics, 29, 2007, p. 79-87.

6.GELGOR, I.E., KARAMAN, A.I., ERCAN, E., Eur J Dent, 1, No. 3, 2007, p. $125-31$.

7.J ANSON, G., GOIZUETA, O., GARIB, D.G., JANSON, M., Angle Orthod, 81, No. 2, 2011, p. 217-21.

8.BACCETI, T., STAHL, F., MCNAMARA J A. J r., Am J Orthod Dentofacial Orthop., 135, no. 2, 2009, p. 148-54.
9.Al-KHATECB, E.A., Al-KHATECB, S.N., Angle Orthod, 79, no. 5, 2009, p. 859-66.

10.SALTAZI, H., FLORESMIR, C., MAZOR, P.W., YOWSEF, M., Angle Orthod, 82, No. 3, 2012, p. 432-40.

11.JACOB, H.B., BUSCHANG, P.H., Angle Orthod, 84, No. 4, 2014, p. 755-61.

12.BISHARA, S.E., CUMMINS, D.M.,ZAHER, A.R., Am J Orthod Dentofacial Orthop, 111, No. 1, 1997, p. 18-27.

13.JANSON, G., GRACIANO, J.T., HENRIQUES, J.F., de FREITAS, M.R., PINZAN, A., PINZAN-VARCELINO, C.R., Am J Orthod Dentofacial Orthop, 129, No. 6, 2006, p. 759-67.

14.J ANSON, G., SATHLER, R., FERNANDES, T.F., ZANDA, M., PINZAN, A., J Appl Oral Sci, 18, No. 4, 2010, p. 397-402.

15.TSENG, L., CHANG, C.H., ROBERTS, W.E., Int J Orthod Implantol, 38, 2015, p. 54-72.

16.PROFFIT, W.R., FIELDS, H.W. J r., SARVER, D.M., Contemporary orthodontics, 4th ed., St. Louis: Mosby Elsevier, 2007.

17.BRANTLEY, W.A., Angle Orthod, 49, No. 3, 1979, p. 37-43.

18.OC-ORTHODONTICS, OC-ORTHODONTICS, 2018. Online. Available: https://ww w.dropbox.com/s/edsow 19zcz2nzuz2018\%200C\%20 Catalog\%20Rev.\%20T\%20-\%200nline.pdf?dl=0.

19.BACCETI, T., FRANCHI, L., MCNAMARA, J.A., Sem. Orthod., 11, 2005, p. 119-129.

20.LILE, I.E., VASCA, E., HOSSZU, T., FREIMAN, P., VASCA, V., BUNGAU, S., VAIDA, L., Mat. Plast., 52, no. 2, 2015, p. 175-9.

21.VAIDA, L., MOLDOVAN, L., LILE, I.E., TODOR, B.I., PORUMB, A., TIG I., BRATU, D.C., Mat. Plast, 52, no. 3, 2015, p. 364-7.

22.LIRA, A.L., GOMES-SOUZA, M.M., BOLOGNESE, A.M., NOJIMA, M., Braz. J. Oral Sci., 13, No. 4, Oct-Dec 2014, p. 251-6.

23.REDDY, P., KHARABANDA, O.P., DUGGAL, P., PARKASH, H., Am J Orthod Dentofacial Orthop, 118, No. 6, 2000, p. 641-8.

24.ELLEN, E.K., SCHNEIDER, B.J., SELLKE, T., Am J Orthod Dentofacial Orthop, 114, No. 4, 1998, p. 430-6.

25.NELSON, B., HANSEN, K., HEAGG, U., Am J Orthod Dentofacial Orthop, 115, No. 1, 1999, p. 13-23.

26.HEINIG, N., GOZ, G.R., J Orofac Orthop, 6, 2001, p. 436-50.

27.ABHAY, K.J., ANAND, K.P., GANESHKAR, S.V., SANGAMESH, B., CHUGH, T., Contemp Clin Dent, 3, No. 3, 2012, p. 334-37.

28.NELSON, B., HANSEN, K., HEAGG, U., Am J Orthod Dentofacial Orthop, 118, No. 2, 2000, p. 142-9.

29.SERBESIS-TSARADIS, C., PANCHERZ, H., Angle Orthod, 78, No. 5, 2008, p. 813-8.

30.COMBRINK, F.J ., STEYN, C.L., HUDSON, A.P., SADJ , 61, No. 8, 2006, p. 344-50.

31.J AYACHANDRAN, S., WILTSHIRE, W.A., HAYASAKI, S.M., PINHEIRO, F.H., Am J Orthod Dentofacial Orthop, 150, No. 6, 2016, p. 979-88.

32.J ONES, G., BUSCHANG, P.H., KIM, K.B., OLIVER, D.R., Angle Orthod, 78, No. 2, 2008, p. 332-8.

33.J ANSON, G., STAHLER, R., FERNANDES, T.F., BRANCO, N.C., de FREITASE, B.R., J Orthod Dentofacial Orthop, 143, No. 3, 2013, p. 38392.

34.KANCHANA, P., GODFREY, K., Am J Orthod, 118, No. 3, 2000, p. 280 7.

35.WANG, T., ZHOU, G., TAN, X., DONG, Y., Angle Orthod, 77, No. 4, 2007, p. 688-93.

36.CHANG, C.H., ROBERTS, W.E., Int J Orthod Implantol, 30, 2013, p. 76-8.

37.CHANG, C.H., ROBERTS, W.E., Int J Orthod Implantol, 32, 2013, p. 80-9.

38.VAIDA, L., COREGA, C., ROSEANU, G., Journal of Cognitive and Behaviour Psychotherapies, 9, No. 2, 2009, p. 131-3.

39.VAIDA, L., PIRTE, A., COREGA, C., SLAVESCU, D., MUTIU, G., Romania J ournal of Morphology and Embryology, 50, No. 4, 2009, p. 625-9.

40.RADESCU, O., ALBU, S., BACIUT, M., BRAN, S., COMAN, A.C., BECHIR, E.S., PACURAR, M., TODEA, D., Rev. Mat. Plast., 54, no. 3, 2017, p. 473-476.

41.OTELEA, M.R., TRENCHEA, M., ARGHIR, O.C., VELESCU, L., DANTES, E., BECHIR, E.S., ELSAAFIN, M., RASCU, A., Rev. Chim. (Bucharest), 69, no. 1, 2018, p. 282-285.

Manuscript received: 28.02 .2019 